\title{
Rhizobia Can Induce Nodules in White Clover by "Hijacking" Mature Cortical Cells Activated During Lateral Root Development
}

\author{
Ulrike Mathesius, Jeremy J. Weinman, Barry G. Rolfe, and Michael A. Djordjevic \\ Plant Microbe Interaction Group, Research School of Biological Sciences, Australian National University, \\ GPO Box 475, Canberra ACT 2601, Australia \\ Accepted 15 October 1999.
}

\begin{abstract}
We examined a range of responses of root cortical cells to Rhizobium sp. inoculation to investigate why rhizobia preferentially nodulate legume roots in the zone of emerging root hairs, but generally fail to nodulate the mature root. We tested whether the inability to form nodules in the mature root is due to a lack of plant flavonoids to induce the bacterial genes required for nodulation or a failure of mature cortical cells to respond to Rhizobium spp. When rhizobia were inoculated in the zone of emerging root hairs, changes in $\beta$-glucuronidase (GUS) expression from an auxin-responsive promoter (GH3), expression from three chalcone synthase promoters, and the accumulation of specific flavonoid compounds occurred in cortical cells prior to nodule formation. Rhizobia failed to induce these responses when inoculated in the mature root, even when co-inoculated with nod gene-inducing flavonoids. However, mature root hairs remained responsive to rhizobia and could support infection thread formation. This suggests that a deficiency in signal transduction is the reason for nodulation failure in the mature root. However, nodules could be initiated in the mature root at sites of lateral root emergence. A comparison between lateral root and nodule formation showed that similar patterns of GH3:gusA expression, chalcone synthase gene expression, and accumulation of a particular flavonoid compound occurred in the cortical cells involved in both processes. The results suggest that rhizobia can "hijack" cortical cells next to lateral root emergence sites because some of the early responses required for nodule formation have already been activated by the plant in those cells.
\end{abstract}

Additional keywords: auxin transport inhibition, cytokinin, lateral root formation.

Soil bacteria of the genera Rhizobium, Sinorhizobium, Bradyrhizobium, Azorhizobium, and Mesorhizobium, generically called "rhizobia," can form nodules on roots of legume plants. Nodules are new plant organs that are initiated in the root cortex by Rhizobium spp. signal molecules called lipochitin-oligosaccharides (LCOs) (Dénarié et al. 1996; Spaink 1996). LCOs are produced by rhizobia in response to fla-

Corresponding author: Ulrike Mathesius: Telephone: + 6126249 3087; Fax: + 6126249 0754; E-mail: ulrike@ rsbs.anu.edu.au vonoid compounds that are exuded by legume roots and act as both chemoattractants (Caetano-Anollés et al. 1988; Phillips 1992) and activators of the Rhizobium spp. genes required for LCO production (Redmond et al. 1986), generically called nodulation (nod) genes.

In most legumes, root nodules are preferentially initiated in cortical tissues just behind the root tip in the zone of root hair emergence where several root tissues (for example, root hairs) are still developing (Bhuvaneswari et al. 1980, 1981). The ability of rhizobia to induce nodules in tissues that are already mature is greatly diminished (Bhuvaneswari et al. 1981). One of the reasons put forward for this failure to nodulate in the mature region is the lack of actively growing roots hairs that are an integral requirement for both successful infection thread formation and initiation of the nodulation process (Bhuvaneswari et al. 1981). However, rhizobia can often induce new root hairs to differentiate and grow in mature regions (van Brussel et al. 1992), and "new" root hairs are formed by promoting branching of existing mature root hairs (Fåhraeus 1957). Another reason put forward for the preference to nodulate at certain sites along the root is the preferential release of flavonoids from the zone just behind the root tip that stimulates LCO production in rhizobia (Redmond et al. 1986). Other regions of the plant root surface are thought to produce excessive quantities of anti-inducers of nodulation gene expression and hence would be expected to inhibit LCO production (Djordjevic et al. 1987; Rolfe 1988).

When nodules are induced in the mature root zone they are often associated with the formation of lateral roots (Nutman 1948, 1956). Typically, these lateral root-associated nodules (LRANs; Fig. 1A) occur at the junction point of primary lateral roots and the main root. To our knowledge, it has not been investigated if LRANs originate from the cortex of the emerging lateral root or the main root. During nodule formation in peanut, cortical cells of the main root adjacent to an emerged lateral root are stimulated to develop into a nodule (Chandler 1978). However, in some plants, nodule development originates from cells of lateral roots. For example, in Sesbania spp., nodules originate from cortical cells at the bases of emerging adventitious or lateral root primordia (Tsien et al. 1983). In the non-legume Parasponia sp. and in actinorhizal plants (e.g., Casuarina and Alnus spp.), nodules originate from lateral roots that are later modified by rhizobia to form nodules (for review see Hirsch and LaRue 1997). Even 

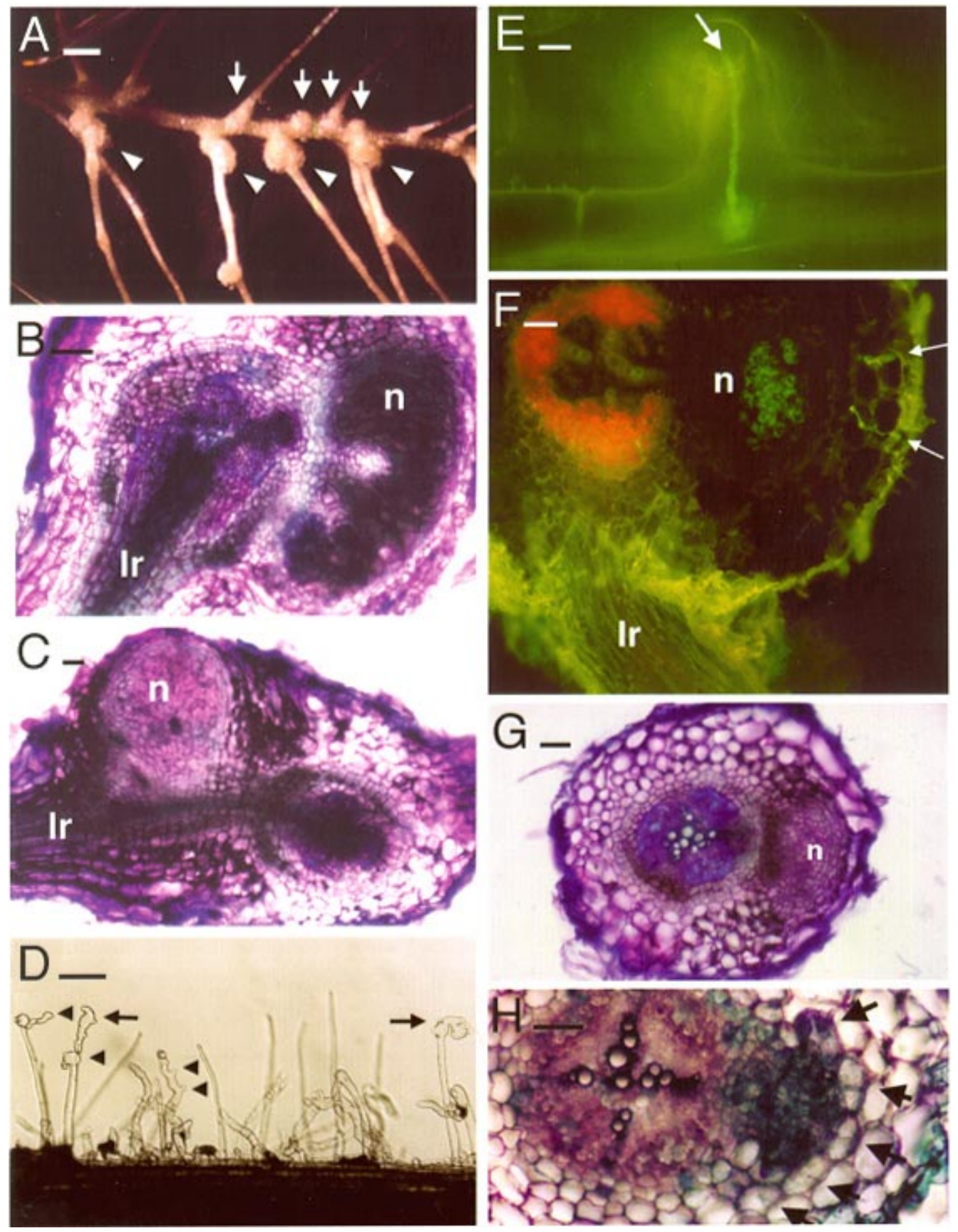

Fig. 1. Features of lateral root-associated nodules (LRANs). A, Typical LRANs on roots of white clover flood-inoculated in zone 2. LRANs originated from either the main root cortex (arrows) or the base of emerged lateral roots (arrow heads). B and C, Main root cross sections showing an LRAN (n) originating from (B) the main root cortex next to an emerged lateral root (lr) and (C) the emerged lateral root (lr). D, Root hair deformations in root hairs in zone 2 inoculated with strain ANU843, including swelling and deformation (arrows) and branching (arrow heads). E, A curled root hair formed $48 \mathrm{~h}$ post inoculation (p.i.) of strain ANU843(GFP) in zone 2. An infection thread has formed in the root hair (arrow). F, An LRAN primordium (n) adjacent to an emerged lateral root (lr) following inoculation of strain ANU843(GFP) in zone 2. Two infection threads are visible (arrows) that have formed 1 week p.i. and extend from the root surface through the outer cortex layers into the nodule primordium. Green fluorescent protein (GFP) fluorescence is also visible in the center of the nodule primordium. Cell walls show yellow autofluorescence, especially at the site of lateral root emergence. G, Nodule primordium-like structure (n) initiated in zone 2 by local application of $10^{-4} \mathrm{M}$ cytokinin (BAP) after 10 days. $\mathbf{H}$, Cortical cell divisions (arrows) occur in the main root adjacent to an emerging lateral root primordium of an uninoculated root. Magnification bars: A, $2 \mathrm{~mm}$; B-D, F, and $\mathbf{G}, 75 \mu \mathrm{m} ; \mathbf{H}, 50 \mu \mathrm{m} ; \mathbf{E}, 20 \mu \mathrm{m}$. 
though lateral roots are initiated from the pericycle, cortical divisions have been observed to occur in the main root adjacent to a lateral root primordium in a number of species (Tschermak-Woess and Dolezal 1953; McCully 1975).

Recently, using white clover, we have shown that spot inoculation of clover nodulating rhizobia in the zone of emerging root hairs, the most susceptible zone for nodulation, leads to a complex modulation of expression of an auxin-responsive reporter, GH3:gusA (Mathesius et al. 1998b), a useful marker reflecting the auxin distribution in plants ( $\mathrm{Li}$ et al. 1999). Concomitantly, a rapid induction of a chalcone synthase reporter (CHS3:gusA) and a rapid accumulation of a flavonoid compound (a derivative of 7,4'-dihydroxyflavone, DHF) occur in the responding inner cortical cells that constitute the nodule progenitor cells (Mathesius et al. 1998a). Later during nodule primordium initiation, the isoflavone formononetin accumulates in the primordium cells. The DHF derivative and formononetin give distinctive fluorescence emission spectra that can be detected in single cells in fresh root sections with a microspectrofluorometer (Mathesius et al. 1998a). These changes in transgene expression and flavonoid synthesis only occur after inoculation with nodulating Rhizobium strains and their LCOs, whereas mutant or heterologous Rhizobium

Table 1. Nodulation efficiency in zone 1 and zone $2^{\mathrm{a}}$

\begin{tabular}{lccc}
\hline & \multicolumn{2}{c}{ ANU843 } & ANU843 + DHF \\
\cline { 2 - 3 } Type of response & Zone 1 & Zone 2 & Zone 2 \\
\hline No. of inoculated rooted leaves & 26 & 26 & 25 \\
Single nodules at bead & 14 & 3 & 3 \\
LRANs at bead & 6 & 3 & 3 \\
Without nodule at bead & 6 & 20 & 19 \\
LRANs at lateral root base & 1 & 5 & 8 \\
nearby, but not at bead & & & \\
a & Rooted leaves or seedlings of white clover were spot inoculated with \\
strain ANU843 in either zone 1 or 2. Nodules were counted at the site \\
of the inoculation bead 10 days post inoculation and classed as either \\
single nodules (nodules not associated with lateral roots) or lateral \\
root-associated nodules (LRANs). Additionally, LRANs that had de- \\
veloped at lateral root bases near the inoculation site were recorded. \\
b Effect of 7,4'-dihydroxyflavone (DHF) provision to rhizobia. Only one \\
experiment is shown; however, the experiment was conducted twice \\
with similar results.
\end{tabular}

strains fail to induce these typical responses and the formation of nodules (Mathesius et al. 1998a, 1998b). The responses also clearly precede nodule initiation and occur in the nodule progenitor cells. These results suggest that changes in auxin transport and flavonoid pathway activation are necessary for nodule formation. Similar conclusions were drawn from nodulation studies in vetch, where auxin transport inhibition was also found to be a specific response to nodulating rhizobia and LCOs (Boot et al. 1999). Clearly, changes in the expression of GH3:gusA and CHS3:gusA, and the accumulation of flavonoids, are all useful markers for the very earliest stages of nodule initiation and development and indicate successful signal transduction events in white clover.

In this study we have compared the induction of root nodules in the zone of emerging root hairs ("zone 1") with that occurring in the mature root zone ("zone 2") to determine how nodules are induced in zone 2 . Three hypotheses were tested: (i) that nodulation in the mature root is limited by a lack of inducing flavonoids; (ii) that the cortical cells in the mature root do not respond to Rhizobium sp. LCOs; and (iii) that nodulation in zone 2 is dependent upon the process of lateral root formation. First, we tested whether the exogenous addition of the nod gene inducer, DHF, to rhizobia prior to their inoculation in zone 2 was sufficient to enhance their ability to form nodules. Secondly, the expression patterns of several markers for nodule initiation in zone 1, including the GH3:gusA and three different $C H S$ :gusA transgenes, and the accumulation of specific flavonoids, were studied in zone 2 following inoculation with clover nodulating rhizobia. Thirdly, we examined CHS:gusA and GH3:gusA expression and flavonoid accumulation in zone 1 and at sites of lateral root emergence in the absence of rhizobia to find out what distinguishes these zones from regions where nodules cannot be formed.

\section{RESULTS}

\section{Nodule initiation in mature white clover roots is infrequent and occurs preferentially at sites of lateral root emergence.}

The nodulation ability of $R$. leguminosarum bv. trifolii (strain ANU843) was determined after spot inoculation either in the

Table 2. Response of auxin-responsive and chalcone synthase reporter constructs in transgenic white clover roots following Rhizobium sp. inoculation in zones 1 and $2^{\mathrm{a}}$

\begin{tabular}{|c|c|c|c|c|c|c|}
\hline Promoter & Time p.i. (h) & Response $^{\text {b }}$ & Responding tissue & ANU843, zone 1 & ANU843, zone 2 & ANU843 + DHF, zone $2^{c}$ \\
\hline GH3 & 5 & Acropetal $\downarrow$ & Stele & $5 / 7$ & $0 / 9$ & $0 / 10$ \\
\hline GH3 & 16 & Acropetal $\downarrow$ & Stele & $7 / 10$ & $0 / 10$ & $0 / 10$ \\
\hline GH3 & 24 & Local $\uparrow$ & Cortex & $9 / 14$ & $0 / 10$ & $0 / 12$ \\
\hline GH3 & 48 & Local $\uparrow$ & Dividing cortex cells & $9 / 13$ & $0 / 8$ & $0 / 10$ \\
\hline CHS1 & 5 & Local $\uparrow$ & Outer cortex & $2 / 8$ & $0 / 7$ & $0 / 10$ \\
\hline CHS1 & 24 & Local $\uparrow$ & Outer cortex & $9 / 10$ & $0 / 9$ & $5 / 10$ \\
\hline CHS1 & 48 & Local $\uparrow$ & Outer cortex & $9 / 11$ & Not tested & $0 / 6$ \\
\hline CHS2 & 5 & Local $\uparrow$ & Cortex & $0 / 8$ & $0 / 7$ & $0 / 5$ \\
\hline CHS2 & 24 & Local $\uparrow$ & Cortex & $5 / 8$ & $1 / 7$ & $0 / 9$ \\
\hline CHS2 & 48 & Local $\uparrow$ & Cortex & $5 / 7$ & Not tested & $0 / 10$ \\
\hline CHS3 & 5 & Local $\uparrow$ & Inner cortex & $4 / 7$ & $0 / 6$ & $0 / 10$ \\
\hline CHS3 & 24 & Local $\uparrow$ & Inner cortex & $3 / 8$ & $0 / 5$ & $0 / 10$ \\
\hline CHS3 & 48 & Local $\uparrow$ & Dividing cortex cells & $7 / 13$ & Not tested & $0 / 9$ \\
\hline
\end{tabular}

${ }^{a}$ Roots were spot inoculated with strain ANU843 in either zone 1 or zone 2, and the number of roots responding with local changes in transgene expression out of the total number of treated roots wascounted after different incubation times. $\beta$-Glucuronidase (GUS)-stained roots were visually scored for changes in transgene expression compared with mock-inoculated roots. p.i. $=$ post inoculation.

$\mathrm{b} \uparrow=$ up-regulation; $\downarrow=$ down-regulation of transgene expression relative to the inoculation site.

${ }^{\mathrm{c}}$ Effect of the addition of $2 \mu \mathrm{M} 7,4^{\prime}$-dihydroxyflavone (DHF) to strain ANU843 prior to inoculation. 
zone of emerging root hairs (zone 1) or at $3 \mathrm{~cm}$ behind the root tip (zone 2). The spot inoculation site was marked by a small ion exchange bead. To test whether nodulation in zone 2 was inhibited by the lack of inducing flavonoids (first hypothesis), rhizobia were grown in the presence of $2 \mu \mathrm{M}$ DHF. After 10 days, spot inoculation in zone 1 led to a $77 \%$ probability of nodule formation at the inoculation bead and root hair curling was observed in all cases. Inoculation of ANU843 (in the absence of DHF) in zone 2 resulted in only $23 \%$ nodulation at the site and half of these nodules were LRANs (Fig. 1A). Addition of $2 \mu \mathrm{M}$ DHF to the Rhizobium sp. growth medium did not increase the number of nodules or LRANs at the site of inoculation in zone 2. Chi square tests showed that there was a significant $(P=$ 0.0002 ) reduction in nodule numbers in zone 2 (in the presence or absence of DHF), compared with zone 1. Table 1 summarizes the results. Serial sections through LRANs revealed that most of the LRANs originated from the main root cortex adjacent to an emerging lateral root (Fig. 1B), but about $30 \%$ of LRANs originated from the cortex of an emerged lateral root (Fig. 1C). The vascular bundle of LRANs was peripheral as in nodules induced in zone 1, and the overall structures of the nodules formed in zones 1 or 2 were indistinguishable.

\section{Mature root hairs remain responsive to rhizobia.}

In zone 2, root hair deformation, branching, and curling were seen within $24 \mathrm{~h}$ in 18 of 20 roots inoculated with ANU843 both in the presence and absence of DHF (Fig. 1D). Curled root hairs in zone 2 mostly originated from a branching point of an existing root hair. DHF alone did not cause root hair deformations.

To observe the mode of entrance of rhizobia in the mature root, strain ANU843(GFP), which constitutively expresses the green fluorescent protein (GFP), was inoculated in zone 2. In serial sections through LRANs formed 1 week post inoculation (p.i.), infection threads filled with green fluorescent bacteria were visible in several cases (Fig. 1E). Infection threads had penetrated from the root hairs through the cortex to nodule primordia located adjacent to emerged lateral roots (Fig. $1 \mathrm{~F})$. We did not find any evidence for bacteria entering the main root from potential wound sites where lateral roots had penetrated (so-called "crack entry" sites). A time course experiment showed that LRANs connected to the main root emerged either at the same time as lateral roots (about 1 week p.i.) or after lateral roots had already penetrated the main root cortex. From about 2 weeks p.i. onward, LRANs also formed on the emerged lateral roots.

\section{Mature cortex cells respond to cytokinin addition.}

To test whether the deficiency of a Rhizobium sp. in causing cell divisions in zone 2 is due to an inability of mature cortex cells to divide, agar blocks containing cytokinin $\left(10^{-4} \mathrm{M}\right.$ benzyl aminopurine) were placed on 10 roots in zone 2. Cytokinin at this concentration is sufficient to induce cell divisions in the inner cortex when applied in zone 1 (Mathesius 1999). When roots were sectioned after 10 days of cytokinin application in zone 2, inner cortical cell divisions or small, nodulelike primordia were found in every treated root (Fig. 1G).

\section{The number of lateral roots correlates with the number of LRANs.}

We observed that nodules in zone 2 were often associated with lateral roots. We argued that if nodule formation in the mature root is dependent upon the presence of lateral root primordia (third hypothesis), then nodule numbers should increase under conditions that raise lateral root numbers. To test this hypothesis, we increased the number of lateral root foci by excising the root tips of half of the roots at the time of flood inoculation with strain ANU843. Twenty-two rooted leaf plantlets were analyzed for each group. Nodule numbers were counted 2 weeks p.i. and the number of LRANs (Fig. 1A) versus the number of nodules occurring unassociated with a lateral root was distinguished. There was an average of 0.95 and 1.05 unassociated nodules per main root for intact or decapitated roots, respectively. Decapitation of the root tips led to a significant increase in lateral root numbers and to a significant increase in the number of LRANs (both $P<0.05$; Student's $t$ test), compared with intact roots. Intact roots had an average of 0.91 LRANs and 4.3 lateral roots, whereas decapitated roots had an average of 3.38 LRANs and 6.8 lateral roots per main root. The correlation between the number of lateral roots and the number of LRANs was significant $(P<$ $0.005)$ in the decapitated roots, but not significant in the intact roots.

\section{Rhizobium spp. fail to induce transgene expression in cortical cells in zone 2 .}

To test whether the inability to form nodules in zone 2 is a result of a disrupted signal transduction chain (second hypothesis), we monitored several root responses in zone 2 that were found to be activated by nodulating rhizobia in cortical cells prior to successful nodule initiation in zone 1 (Mathesius et al. 1998a, 1998b). Rhizobia were spot inoculated in zone 1 or zone 2 onto the roots of transgenic rooted leaves carrying either the GH3:gusA, CHS1:gusA, CHS2:gusA, or CHS3:gusA transgenes. Rhizobia spot inoculated in zone 2 were unable to induce the time-dependent changes in the expression of GH3:gusA that are induced when rhizobia are spot inoculated in zone 1 (Mathesius et al. 1998b). Neither down-regulation of GH3:gusA between 5 and $16 \mathrm{~h}$ p.i. nor up-regulation of GH3:gusA at the spot inoculation site between 24 and $48 \mathrm{~h}$ p.i. occurred in cortical cells of roots inoculated in zone 2 (Table 2). CHS1:gusA, CHS2:gusA, and CHS3:gusA expression was induced in cortical cells at the spot inoculation site between 5 and $48 \mathrm{~h}$ p.i. when rhizobia were spot inoculated in zone 1 , but failed to be induced after spot inoculation in zone 2 . The pre-incubation of rhizobia with DHF did not overcome the failure of rhizobia to induce these transgenes (Table 2). One exception was the transient induction of CHS1:gusA at $24 \mathrm{~h}$ p.i. when roots were inoculated with ANU843 grown in the presence of DHF in zone 2. However, CHS1:gusA can also be induced by non-nodulating rhizobia and foreign bacteria in zone 1 (Mathesius 1999) and is therefore not a specific marker for successful nodule initiation.

\section{Cortical cells in zone 2 fail to accumulate intracellular flavonoids following Rhizobium sp. infection.}

In addition to $C H S$ gene activation, the induction of intracellular flavonoids by rhizobia was studied after spot inoculation of strain ANU843 in either zone 1 or zone 2. Root sections were viewed under a fluorescence microscope at $24 \mathrm{~h}, 4$ days, 6 days, and 8 days p.i., and flavonoids were made visible in living cells after the addition of diphenylboric acid-2aminoethylester (DPBA). At 24 h p.i., islands of inner cortical 
cells fluorescing orange were observed in nine of 10 roots inoculated in zone 1, as previously reported (Fig. 2A; Mathesius et al. 1998a), whereas only two of 10 roots spot inoculated in zone 2 showed orange fluorescence in the inner cortex (Fig. 2B). After 4 days, nine of 10 roots inoculated in zone 1 possessed divided inner cortical cells that contained blue fluorescing compounds. In two of 10 roots inoculated at zone 2, inner cortical cell divisions were detected and these cortex divisions were accompanied by large numbers of pericycle divisions in the same sections (data not shown). After 6 and 8 days, respectively, nine and eight of 10 roots inoculated in zone 1 had a nodule primordium containing blue fluorescence located at the site of the inoculation bead. From 10 roots inoculated in zone 2 , blue fluorescing nodule primordia were seen in four and three roots after 6 and 8 days, respectively. Two each of these primordia were located next to a lateral root (Fig. 2G). Often, the inner cortical cells had only divided a few times and not formed a large nodule primordium after inoculation in zone 2. In some cases, hybrid structures were found with a nodule appearance but a central vascular bundle.

\section{The same fluorescent compounds occur in cortical cells during lateral root and nodule formation.}

The presence of flavonoids in zone 1 and at sites of lateral root emergence, the preferred infection sites along the root, was examined by fluorescence microscopy to determine if these root zones differ from zones where a nodule cannot be induced (third hypothesis). Uninoculated roots were examined first. Roots were sectioned on a vibratome and immediately viewed for fluorescence after treatment with DPBA. We have previously shown (Mathesius et al. 1998a) that zone 1 harbors a small number of cortical cells at the time of inoculation that contain an orange fluorescent compound. A similar orange fluorescence also occurred closer to the root tip in most differentiating cortical and stelar cells (Fig. 2C). In the mature region of the root, starting from the zone of mature root hairs and extending into zone 2, most mature cortex cells did not fluoresce, but the cell walls of cortex cells showed autofluorescence.

We then focused on the process of lateral root formation. Groups of synchronously divided pericycle cells overlying a xylem pole, which were likely to form a lateral root primordium, were accompanied by orange fluorescing cortex cells overlying these rows of pericycle cells (Fig. 2D). Examination of 60 root sections of 12 roots in zone 2 showed that groups of dividing pericycle cells (as shown in Figure 2D) were accompanied by fluorescent cortex cells in $62 \%$ of the cases, whereas the fluorescent cortical cells overlying undivided pericycle cells occurred in only $2 \%$ of the cases. When a lateral root primordium was formed, cells of the primordium fluoresced blue and the emerging primordium was surrounded by orange fluorescing cortex cells (Fig. 2E). Cortex cells in front of an emerging lateral root primordium were found to be dividing in about $25 \%$ of the analyzed sections (Fig. 1H). After emergence of a lateral root from the main root, cortical cells in the main root at the site of breakthrough also fluoresced orange (Fig. 2F). The blue fluorescence of dividing cells of a lateral root primordium was similar to blue fluorescence detected in nodule primordia (Fig. 2G). In differentiated lateral roots, the fluorescence pattern in the root tip was identical to that in the main root, with meristematic cells of the root tip fluorescing blue, apparently in the nuclei (Fig. $2 \mathrm{H}$ ), and cortex cells in the zone of emerging root hairs (equivalent to zone 1 of the main root) fluorescing orange.

To characterize the fluorescent compounds detected in white clover roots in situ, the emission spectra of the fluorescent cell contents were measured with a microspectrofluorometer under three conditions: (i) autofluorescence; (ii) fluorescence induced by DPBA; and (iii) fluorescence after incubation in $\mathrm{NH}_{4} \mathrm{OH}$ (without prior incubation in DPBA) to standardize the $\mathrm{pH}$ in each cell. Fluorescence emission spectra of orange fluorescent contents of cortex cells (i) in zone 1, (ii) underlying Rhizobium sp. infection sites (Fig. 2A), and (iii) next to emerging lateral roots (Fig. 2D-F), were very similar to each other under each of the three conditions (Fig. 3A-C). Spectra recorded from blue fluorescing compounds inside cells found in the meristematic zone of the root tip (shown in Fig. 2H) matched spectra recorded from compounds in dividing cells in both nodule and lateral root primordia, as shown in Figure 2G (Fig. 3D-F).

\section{Identification of fluorescent compounds in lateral roots and nodules.}

High-pressure liquid chromatography (HPLC) analysis of root extracts of mock-inoculated roots containing lateral roots of different stages and of roots inoculated with strain ANU843 showed that the same compounds (labeled 1 to 9) were present in both cases (Fig. 4A,B). However, four of these compounds (compounds $3,6,7$, and 8$)$ were significantly $(P<0.05)$ upregulated in strain ANU843-inoculated roots within $24 \mathrm{~h}$ p.i.; one compound (number 9$)$ was significantly $(P<0.05)$ downregulated (Fig. 4B). One week p.i., the inoculated roots showed significantly up-regulated levels of compounds 3 and 9 compared with mock-inoculated roots (Fig. 4C). We have

Fig. 2. Detection of intracellular fluorescent compounds in root sections of white clover during nodule and lateral root development. All sections were stained with the flavonoid-specific dye diphenylboric acid-2-aminoethylester (DPBA). Because of differences in exposure time, fluorescence referred to as "orange" does not appear orange on the prints in all cases, but the emission spectra of the orange fluorescing cells were very similar, as shown in Figure 3. A, "Orange" fluorescence occurs in inner cortical cells (arrows) 24 h post inoculation (p.i.) with strain ANU843 in zone 1. B, No "orange" fluorescence occurs in cortical cells of roots $24 \mathrm{~h}$ p.i. with strain ANU843 in zone 2. Inoculation bead on root surface is shown (b). C, Orange fluorescence occurs in all developing cortical and stelar cells in a zone between root meristem and zone 1. D, A group of pericycle cells (blue fluorescent between arrow heads) has just divided synchronously, representing the first step of lateral root development. Following the pericycle divisions, a group of inner cortical cells overlying the divided pericycle cells fluoresces "orange" (arrows). The endodermis (e; casparian strip visible as white fluorescence in anticlinal cell walls) fluoresces green-blue. E, During emergence of a lateral root primordium (lr), cortical cells in front of the primordium fluoresce "orange" (arrows). Lateral root primordium (lr) fluoresces blue in the meristem and base and yellow in the differentiating root cap. Strong autofluorescence occurs in cell walls of the phloem (p) and xylem (x). Root outline is indicated by white dots. F, After breakthrough of a lateral root through the main root, cortical cells adjacent to the lateral root fluoresce orange (arrows). G, Blue fluorescent nodule primordium (n) induced 6 days p.i. of strain ANU843 in zone 2, associated with a blue fluorescent lateral root primordium (lr). H, Blue fluorescence in meristematic cells in the root tip. Fluorescence appears to be located in the nuclei. Magnification bars: A-C, E, F, and G, $50 \mu \mathrm{m} ; \mathbf{D}$ and $\mathbf{H}, 25 \mu \mathrm{m}$. 
previously shown that compound 3 is a derivative of DHF and that compound 9 has chromatographic and fluorescent properties identical to those of formononetin (Mathesius et al. 1998a). No fluorescent or UV-absorbent compounds were detected in extracts of strain ANU843 (Fig. 4D).

Of the nine compounds, only six were fluorescent under UV light, and their fluorescence emission spectra were recorded with a microspectrofluorometer (Mathesius et al. 1998a). When the emission spectra of orange fluorescent cortex cells (either adjacent to an emerging lateral root, or underlying the infection site of strain ANU843, or in mock-inoculated roots just behind the root tip, as shown in Figure 3A-C) were compared with the spectra of the HPLC-purified compounds, only the spectrum of compound 3, a DHF derivative, matched the spectra of the orange fluorescence in each type of the cortical cells under all three conditions (Mathesius et al. 1998a). The only spectrum of
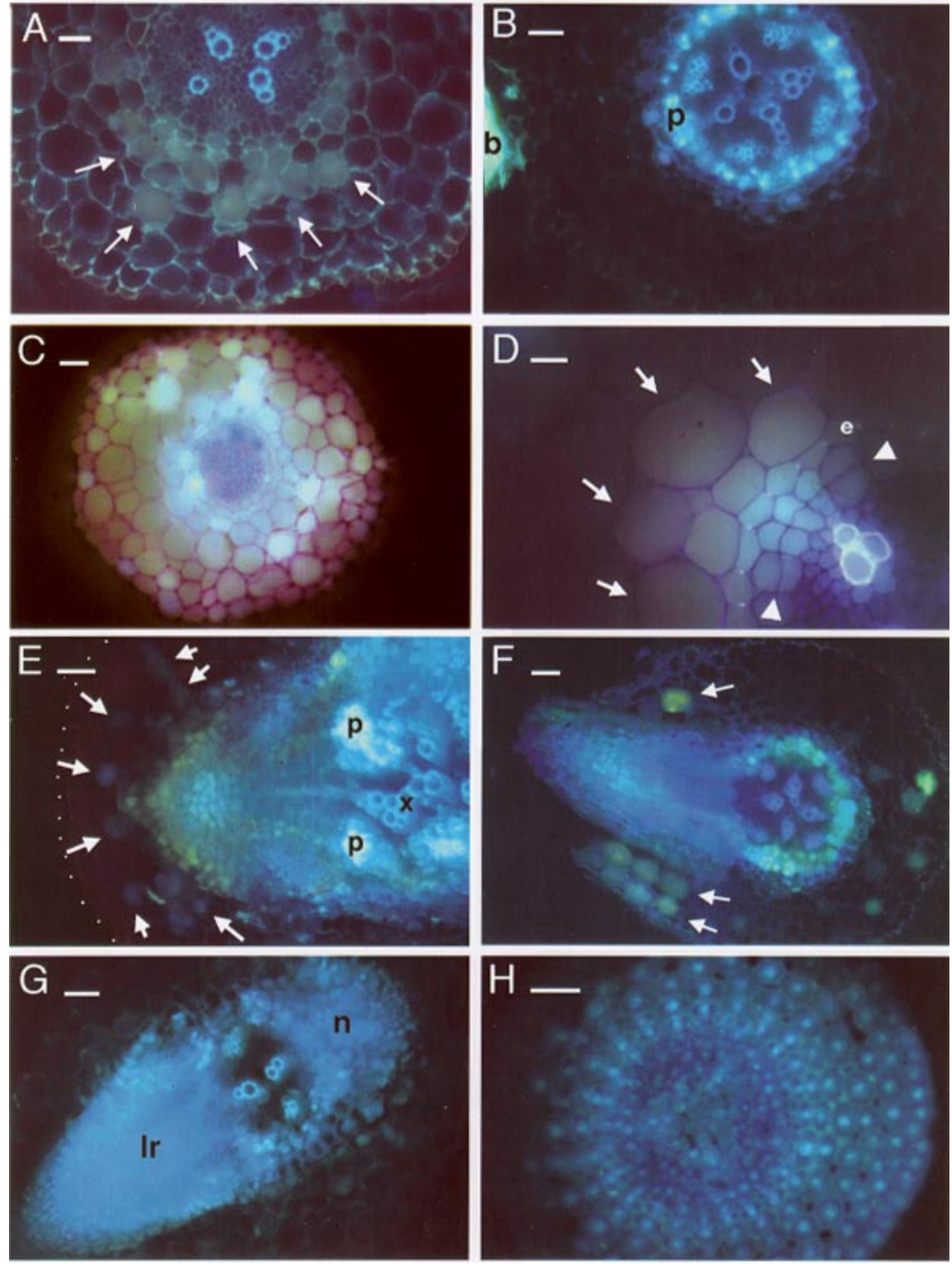
a purified compound from white clover roots that matched the spectra of the blue fluorescing compound detected in nodule and lateral root primordia and in meristematic cells of the root tip under all three conditions (as shown in Figure 3D-F) was the spectrum recorded of peak 9 , which was identical to the spectrum of formononetin (Mathesius et al. 1998a).

\section{Chalcone synthase expression overlaps}

\section{with the accumulation of flavonoids in the root tip} and during lateral root formation.

The expression of CHS1:gusA, CHS2:gusA, and CHS3: gusA was studied in the root tip area and during lateral root development in the absence of rhizobia. Both CHS2:gusA and CHS3:gusA were expressed in the meristematic zone of the root tip of main roots (Fig. 5A) where flavonoids were found (cf. Fig. 2H). CHS1:gusA expression occurred in the root cap (data not shown). During lateral root formation, CHS1:gusA and CHS3:gusA expression was located in the dividing pericycle cells and in inner cortical cells overlying those dividing pericycle cells (Fig. 5B), where flavonoids were located (cf. Fig. 2D). Transgene expression did not occur in the lateral root primordia but was seen in the cortical cells in front of the emerging lateral root primordium (Fig. 5C; cf. Fig. 2E for flavonoids). CHS2:gusA expression did not occur in dividing

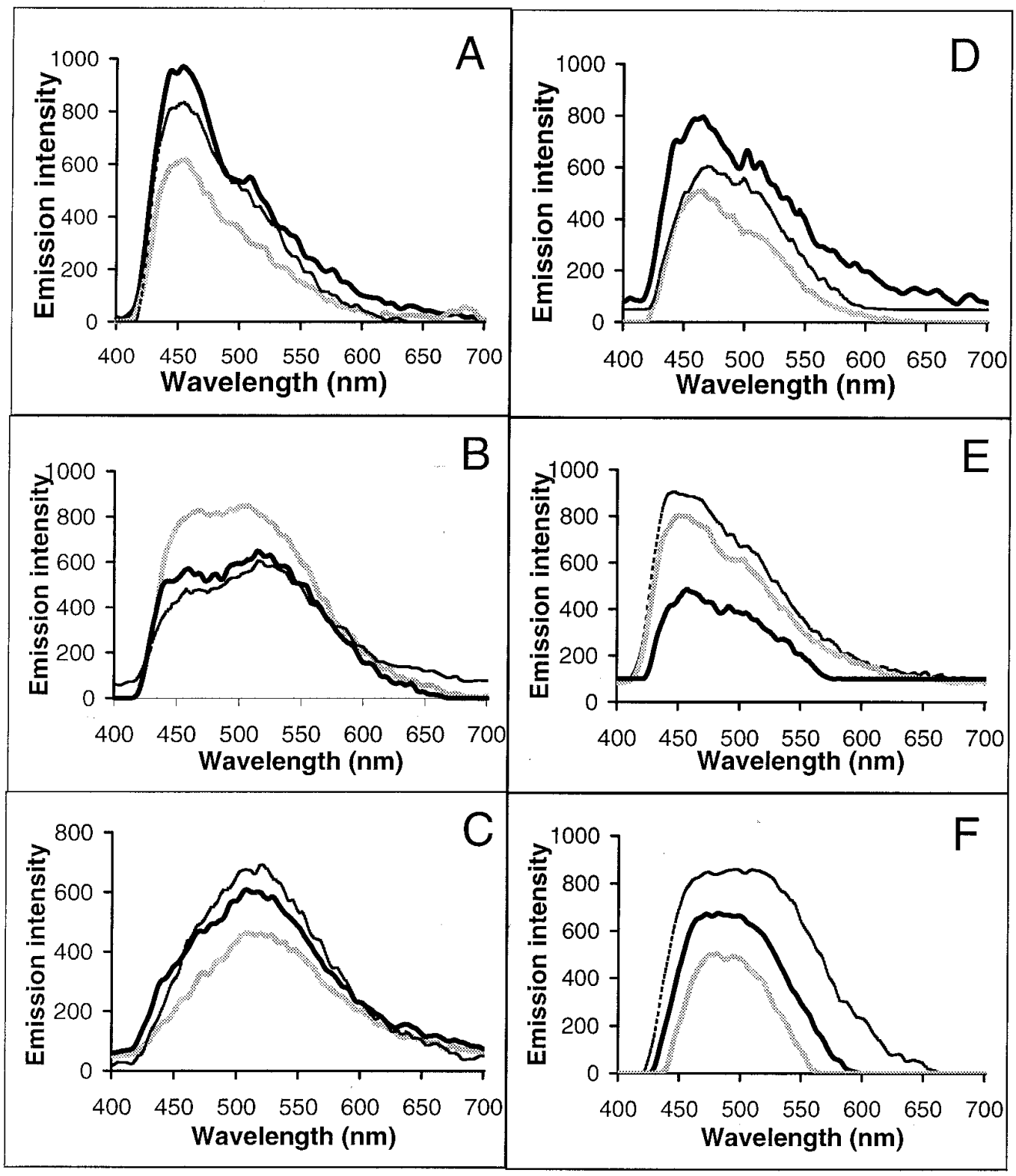

Fig. 3. Fluorescence emission spectra of fluorescent contents of single cells of sections of white clover roots recorded with a microspectrofluorometer Spectra were either recorded (A, D) as autofluorescence, $(\mathbf{B}, \mathbf{E})$ after application of diphenylboric acid-2-aminoethylester (DPBA) to the sections, or $(\mathbf{C}$, F) after separate addition of $\mathrm{NH}_{4} \mathrm{OH}$ to untreated sections. A-C, Emission spectra of an "orange" fluorescent compound in cortical cells located in zone 1 in uninoculated roots (gray thick line), 24 hours post inoculation (p.i.) of strain ANU843 in zone 1 (black thick line), and in front of an emerging lateral root primordium (black thin line). D-F, Emission spectra of a blue fluorescent compound occurring in nodule primordia (thick black line), in meristematic cells in the root tip (thick gray line), or in lateral root primordia (thin black line). 
pericycle cells (data not shown) but was restricted to cortical cells next to the emerging lateral root, especially after breakthrough of the lateral root through the main root cortex (Fig. 5D; cf. Fig. 2F for flavonoid accumulation).

\section{DISCUSSION}

\section{Rhizobia are unable to induce nodulation-specific responses in cortical cells in zone 2 .}

The aim of this study was to examine why and how rhizobia preferentially nodulate legume roots in the zone of emerging root hairs and at sites of lateral root emergence. Spot inoculation experiments confirmed that nodules are preferentially formed when rhizobia are inoculated in zone 1, compared with a low nodulation frequency in zone 2 , as previously reported (Bhuvaneswari et al. 1981). Despite the failure of nodule formation in zone 2, mature root hairs responded to rhizobia and bacterial entry into the mature root still occurred via infection threads, indicating that the initial perception of rhizobia at the root hair is functioning in zone 2. Furthermore, the ability of mature cortical cells to divide in zone 2 in response to cytokinin (BAP) or a nearby lateral root indicated that cortical cells in zone 2 are not generally incompetent to divide. The possibility that a lack of nod gene-inducing flavonoids limits LCO production and hence nodulation in zone 2 was suggestive because the root tip and sites of lateral root emergence are also sites from which nod gene-inducing flavonoids are released (Djordjevic et al. 1987; Rolfe 1988). However, addition of DHF, an active nod gene inducer (Djordjevic et al. 1987), to Rhizobium sp. cells could not compensate for the inability to nodulate, suggesting that it is not the lack of flavonoids or LCOs that inhibits nodulation in zone 2. However, it was found that rhizobia, in either the absence or presence of DHF, were not able to induce the responses in the cortex that nodulating rhizobia actively induce after inoculation in zone 1 and that are followed by nodule formation in zone 1 . These responses include changes in the auxin balance, monitored by the expression from the auxin responsive promoter $G H 3$, the induction of three $C H S$ promoters, and the accumulation of a DHF derivative in undivided cortex cells and of formononetin in nodule primordia (Table 3 ). Therefore, the most likely reason for nodulation failure in zone 2 is a lack of signal transduction from the infected root hair to the underlying cortical cells.

Further research will be necessary to find out which is the first step in the signal transduction chain in the plant root that

Fig. 4. High-pressure liquid chromatography (HPLC) chromatograms of wild-type white clover root extracts during different stages of nodule formation. Absorbance detection (in relative absorbance units [AU]) was at $300 \mathrm{~nm}$. A, Mock-inoculated roots contained seven major compounds (peaks 1, 2, 3, 4, 5, 6, and 9) 24 h post inoculation (p.i.). Peaks 7 and 8 were also present but at very low levels not detectable on the scale used in this chromatogram. B, Roots flood-inoculated with strain ANU843 and extracted 24 h p.i. Peaks 3, 6, 7, and 8 are enhanced compared with controls; peak 9 is almost undetectable. Peak 4 appears induced in this chromatogram, but was not significantly increased $(P<0.05)$ in all individual extracts. C, Roots flood-inoculated with strain ANU843 and extracted 1 week p.i. Peaks 5, 7, and 8 are almost undetectable; peak 9 is induced compared with B. D, Extract of strain ANU843. None of the peaks (1 to 9$)$ are detectable in the bacterial extract. fails to perceive LCOs in zone 2. In zone 1, rapid and near simultaneous effects upon root hairs and underlying cortical and stelar cells occur shortly following rhizobia inoculation (Mathesius et al. 1998a, 1998b; Yang et al. 1994). If, following LCO perception in the root hair, a secondary signal is produced that later moves into the cortex, we would predict that production or transmission of that signal is blocked in mature root hairs. In Arabidopsis it was found that root hair cells become symplastically isolated during differentiation (Ducket et

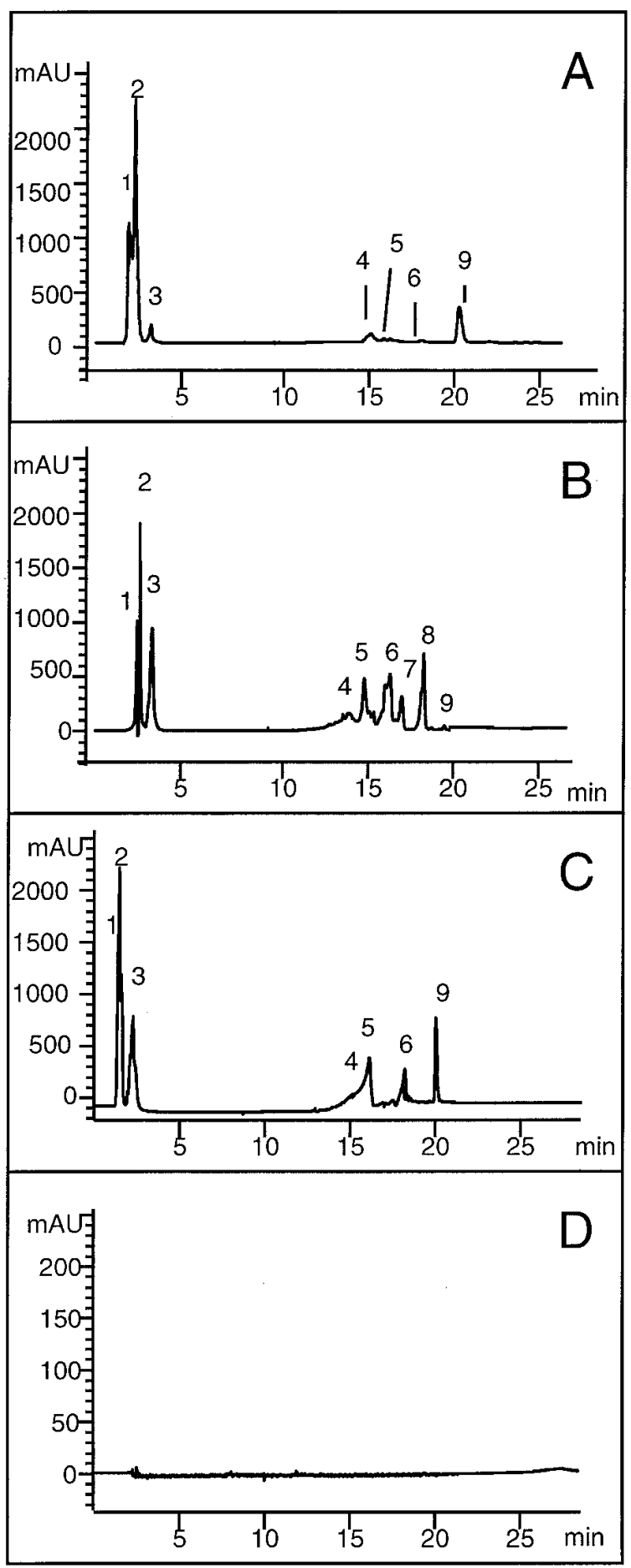


al. 1994), and if this is also true for clover it might explain why root hair cells in zone 2 still respond but cortical cells do not. Alternatively, a secondary signal could be transmitted from the root hair to the cortex but not perceived by mature

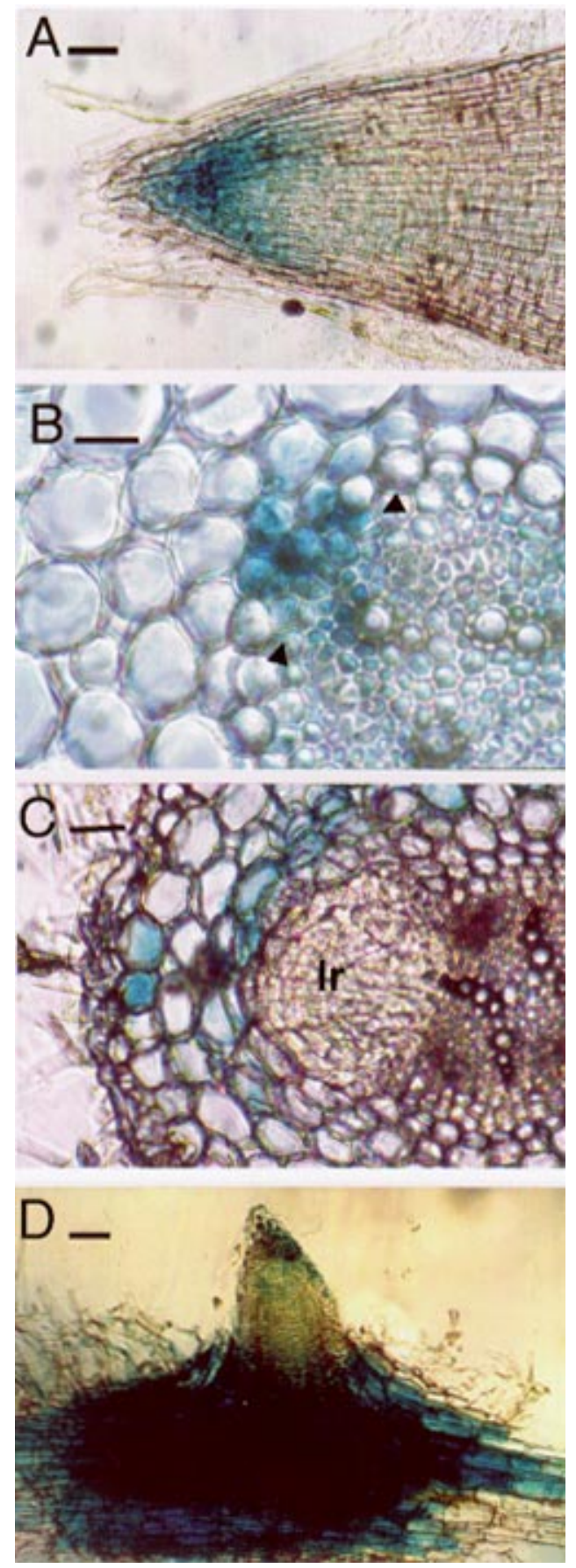

Fig. 5. Expression of CHS: gusA transgenes in white clover during main root and lateral root development. A, CHS2:gusA and CHS3:gusA (shown here) are expressed in root tip meristems of main and lateral roots. B, CHS1:gusA and CHS3:gusA (shown here) expression is detected in dividing pericycle cells (between arrow heads) and in overlying inner cortex cells. C, CHS1:gusA and CHS3:gusA (shown here) expression in cortical cells in front of an emerging lateral root primordium (lr). D, Strong CHS2:gusA expression occurs in cortex of main root at the breakthrough site of a lateral root. Magnification bars: A, C, and D, 50 $\mu \mathrm{m} ; \mathbf{B}, 25 \mu \mathrm{m}$. cortex cells, or mature cortical cells could perceive a signal but not respond to it.

\section{Cortical cells show similar responses during lateral root formation as during nodule formation.}

Even though cortical cells in zone 2 generally fail to respond directly to Rhizobium sp. inoculation, they do exhibit GH3:gusA and flavonoid pathway activity during lateral root formation. Cortex cells in front of emerging lateral roots show the same responses that were found after rhizobia inoculation in zone 1 and in the former are totally LCO independent (Table 3; Fig. 6). These responses include high levels of GH3:gusA expression (Larkin et al. 1996; Mathesius et al. 1998b), CHS1:gusA, CHS2:gusA, and CHS3:gusA activation (Fig. 5), accumulation of a DHF derivative (Fig. 3), and cell divisions (Fig. 1H). The same DHF derivative is also present just behind the root tip (Fig. 2C), and in zone 1 of mockinoculated roots, consistent with its detection in root extracts of mock-inoculated roots (Fig. 4A). Therefore, it appears that the sites of maximum susceptibility to rhizobia infection (zone of emerging root hairs and around emerging lateral roots) are those sites where the described plant responses (summarized in Table 3) can, respectively, be triggered either actively by rhizobia or by a nearby lateral root.

In support of this hypothesis, a significant correlation $(P<$ 0.05 ) between the number of lateral roots on a main root and the number of LRANs was found, and similar results have previously been reported (Nutman 1948). Increasing the numbers of lateral root primordia would result in increased numbers of foci where the described responses (Table 3) are activated in nearby cortical cells. We propose that these activated cortical cells can be "hijacked" by rhizobia for nodule formation (Fig. 6), i.e., rhizobia do not stimulate the responses (Table 3) actively but take advantage of their stimulation by a nearby lateral root. The "hijacked" cortical cells would develop into a nodule connected by new vascular tissue to the main root, leading to the LRAN shown in Figure 1B. Alternatively, cells in the root tip of an emerging lateral root could be infected (by the same mechanism by which a nodule is initiated in zone 1 of the main root), resulting in the LRAN shown in Figure $1 \mathrm{C}$, where the vascular tissue is connected to the

Table 3. Responses of cortex cells following Rhizobium sp. strain ANU843 inoculation in zones 1 and 2 underlying the infection site ${ }^{a}$

\begin{tabular}{lccc}
\hline & \multicolumn{3}{c}{ Location of cortex cells } \\
\cline { 2 - 4 } & & & At sites of \\
Response in cortex cells & Zone $\mathbf{1}$ & Zone 2 & $\begin{array}{c}\text { A } \\
\text { lateral root } \\
\text { formation }\end{array}$ \\
\hline $\begin{array}{l}\text { GH3:gusA expression } \\
\text { CHS1:gusA expression }\end{array}$ & + & - & + \\
CHS2:gusA expression & + & At 24 h p.i. (in & + \\
$\begin{array}{l}\text { CHS3:gusA expression } \\
\text { Accumulation of a DHF }\end{array}$ & + & presence of DHF) & + \\
$\begin{array}{l}\text { derivative } \\
\text { Cell division }\end{array}$ & + & - & + \\
$\begin{array}{l}\text { Accumulation of for- } \\
\text { mononetin }\end{array}$ & + & - & + \\
\hline
\end{tabular}

${ }^{a}$ Responses that occur in zone 1 also occur in cortical cells near sites of emerging lateral root primordia, but not or only occasionally in cortical cells in zone 2.

${ }^{\mathrm{b}}$ p.i. $=$ post inoculation. $\mathrm{DHF}=7,4^{\prime}$-dihydroxyflavone. 
lateral root. The very small number of nodules initiated in the mature root that were not LRANs could have been initiated at a site where pericycle cell divisions were triggered that failed to result in subsequent lateral root formation.

\section{Evolution of nodule formation.}

It is possible that nodule formation in most legumes has evolved from developmental pathways activated during lateral root formation. Firstly, the organogenesis of lateral roots and nodules shares a number of similarities, possibly reflecting similar requirements for developmental signals. For example, several genes that are expressed during nodule formation are also expressed during lateral root development, e.g., ENOD40 (Yang et al. 1993) and ENOD12A (Bauer et al. 1996). We showed here that the same isoflavonoid, previously identified as formononetin (Mathesius et al. 1998a) is produced in the root tip and in lateral root and nodule primordia (Figs. 3 and. $2 \mathrm{G}, \mathrm{H})$. In addition, the same DHF derivative that is induced by rhizobia in zone 1 also occurs just behind the root tip meristem in main and lateral roots (Figs. 3 and 2C,A). However,

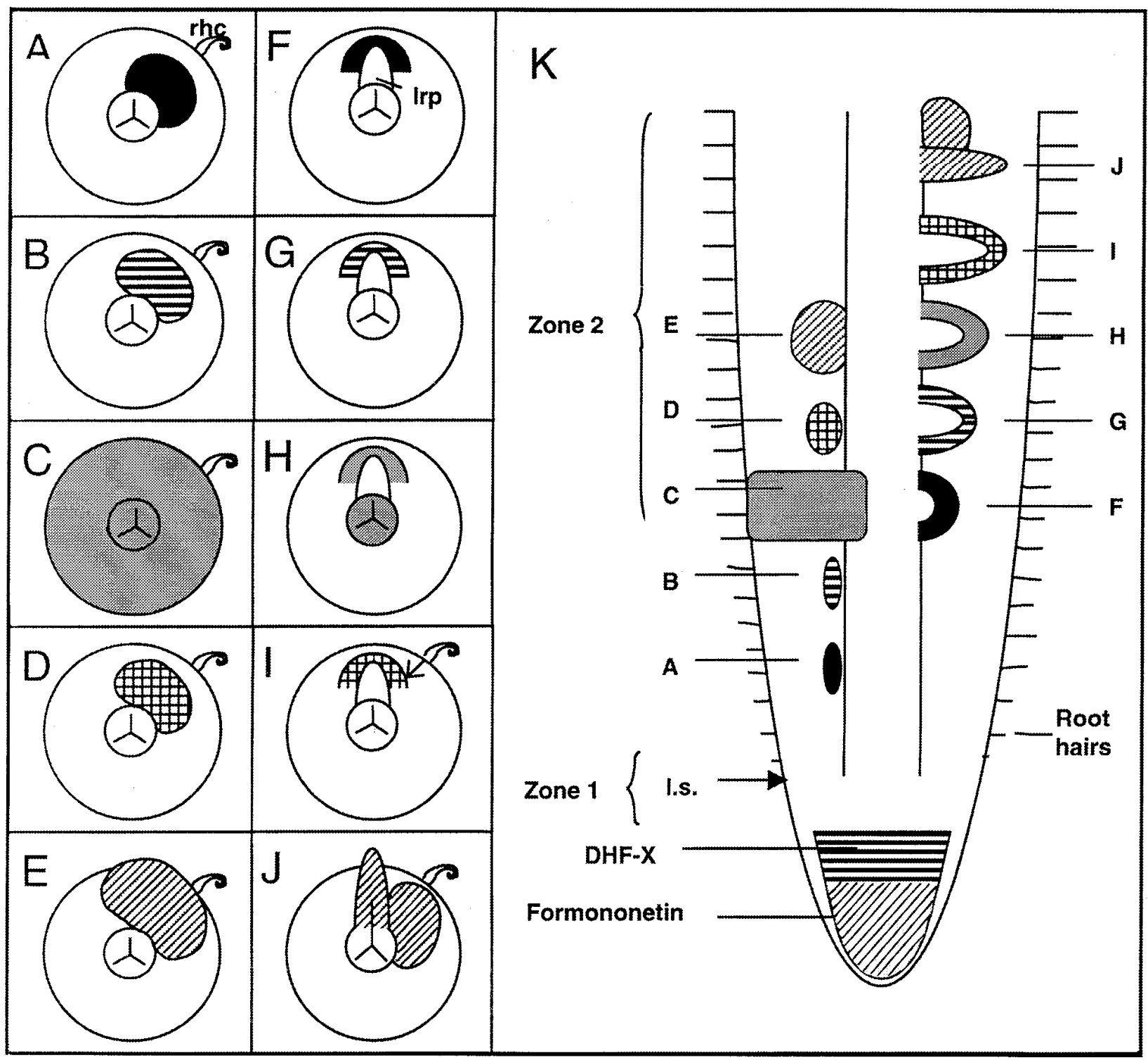

Fig. 6. Comparison of responses in cortex cells during nodule formation in zone 1 (left column) and zone 2 (right column) in white clover. Before inner cortical cell divisions are induced by Rhizobium sp. strain ANU843 at the site of root hair curling (rhc) following inoculation in zone 1, inner cortical cells that are precursors of a nodule primordium are distinguished by (A, black) high CHS3:gusA expression, (B, striped) accumulation of a 7,4'dihydroxyflavone (DHF) derivative, and (C, gray) high GH3: gusA expression. Cortical cells subsequently (D, lattice) divide and (E, striped) grow into a nodule. During lateral root formation, cortex cells overlying lateral root primordium (lrp) also show (F, black) CHS3: gusA expression, (G, striped) accumulation of the DHF derivative, and (H, gray) high GH3:gusA expression. Cortex cells surrounding a lateral root primordium (I, lattice) divide. Rhizobium spp. infections (marked by a curled root hair) occurring next to a lateral root primordium target divided cells (arrow) and cause divided cells to differentiate into (J, striped) a lateral root-associated nodule (LRAN). K, Longitudinal representation of responses occurring during nodule (left side of root) and lateral root (right side of root) development. Zones 1 and 2 are indicated and inoculation site (I. s.) is shown by an arrow. Formononetin and the DHF derivative (DHF-X) are also present in the meristematic and differentiating zones of the root tip of uninoculated roots, respectively. 
the function of formononetin and the DHF derivative in organ formation remains unclear. Nodules and lateral roots also show similar patterns of GH3:gusA expression during comparable developmental stages, suggesting that the requirement for auxin is similar in both organs (Mathesius et al. 1998b). These results are consistent with an origin of nodule formation by signaling pathways already existing in plant development. This hypothesis is supported by the origin of nodules in a Parasponia sp. and in actinorhizal plants from modified lateral roots (Hirsch and LaRue 1997), as well as by the presence of hybrid structures between nodules and lateral roots in legumes (McIver at al. 1993).

In addition to the similarities in organ formation, this study revealed similarities in gene expression in cortical cells stimulated to divide either by an unknown signal from lateral roots or by rhizobia in zone 1 . In the case of peanut nodulation, nodules originate from exactly those cortical cells adjacent to lateral roots that we found to be "activated" during lateral root formation. Therefore, the development of nodules from stimulated cortical cells might have been a second strategy of rhizobia to achieve nodulation and this strategy appears to be a "remnant" in white clover.

However, in most legumes, including alfalfa, soybean, and clover, nodule formation is independent of lateral root formation in zone 1 . Therefore, we suggest that nodule formation from modified lateral roots might have been the initial strategy of rhizobia to initiate nodules, whereas, later during evolution, rhizobia might have extended their strategy to actively stimulate plant responses (including those summarized in Table 3) to induce nodules in zone 1.

We propose that there are two possibilities for nodule initiation in white clover. In zone 1 , rhizobia (via their LCOs) can trigger a number of specific responses in the cortex cells that form the progenitor cells of a nodule (Mathesius et al. 1998a, 1998b). In zone 2, cortical cells near sites of lateral root emergence can be activated during the process of lateral root formation in a similar way as by rhizobia in zone 1 . This second mechanism of cortical cell activation does not require stimulation of the described responses by rhizobia and might therefore give a "second chance" for rhizobia to infect these foci if they fail to induce nodules in zone 1 of the growing root. Nodule differentiation of LRANs in zone 2 would require LCOs subsequent to the initial cortical cell activation by emerging lateral roots. Clearly, both mechanisms differ in the initial trigger for cortical cell activation, but are similar in the type of responses triggered in cortical cells (Fig. 6). The similarity between the two mechanisms of cortical cell activation is supported by the fact that, to our knowledge, there are no clover nodulation mutants that selectively "knock out" nodulation in zone 1 or zone 2 only. We are currently investigating the requirement for flavonoid induction in different root zones in a number of pea nodulation mutants.

\section{MATERIALS AND METHODS}

\section{Plant growth conditions and treatments.}

White clover (Trifolium repens cv. Haifa) wild-type and transgenic plants were maintained in pots in a glasshouse under a shade cloth. Temperatures varied between 19 and $25^{\circ} \mathrm{C}$. For all experiments with white clover we used the rooted leaf bioassay (Rolfe and McIver 1996) for the generation of clonal roots under sterile conditions. Alternatively, white clover seedlings were grown as described in Mathesius et al. (1998a). Roots of rooted leaves were grown and spot inoculated with Rhizobium leguminosarum bv. trifolii (strain ANU843) as described (Mathesius et al. 1998b). Flood inoculation of roots was done with a $10-\mu$ l bacterial culture of strain ANU843 grown in liquid BMM medium (Rolfe et al. 1980) to log phase $\left(\mathrm{OD}_{600}=0.2\right)$ with or without the addition of $2 \mu \mathrm{M} \mathrm{DHF}$ (Indofine Chemicals, Somerville, NJ) during growth of the culture. DHF is the most active nod gene inducer in clover and induces the nod genes required for LCO synthesis at that concentration within minutes (Djordjevic et al. 1987).

For analysis of nodule numbers and detection of flavonoids by fluorescence microscopy and microspectrofluorometry, wild-type white clover plants were used. For analysis of transgene expression, four independent lines of GH3:gusA and two lines each of CHS1:gusA, CHS2:gusA, and CHS3:gusA transgenic white clover plants were examined. Histochemical GUS staining was done as described in Mathesius et al. (1998b). Cytokinin blocks made of $1 \%$ sterile agarose (Progen, Darra, Australia) containing $10^{-4}$ M 6-benzyl aminopurine (Sigma Chemicals, St. Louis, MO) were cut with a sterile razor blade into cubes of approximately $2 \mathrm{~mm}$ side length, placed on roots in zone 2 and left for 10 days.

\section{Generation of transgenic plants.}

Transgenic white clovers containing the GH3:gusA or CHS3:gusA transgenes were described previously (Mathesius et al. 1998a, 1998b). Transgenic white clovers containing the chimeric reporter genes CHS2:gusA (encoded on pJJ402) and CHS1:gusA (encoded on plasmid pMAD10; Djordjevic et al. 1997) were generated by Agrobacterium tumefaciensmediated transformation as previously described (Larkin et al. 1996). The CHS2:gusA construct in pJJ402 utilizes the same gusA coding sequence and $3^{\prime}$ vicilin sequence as the CHS1:gusA, CHS3:gusA and GH3:gusA chimeric genes described previously (Djordjevic et al. 1997; Larkin et al. 1996), differing only in the approximately $1.2-\mathrm{kb}$ sequence to the $5^{\prime}$ side of the gusA initiator codon. This was assembled following in vitro mutagenesis of the Trifolium subterraneum $\mathrm{CHS} 2$ gene (Arioli et al. 1994) with the oligo 5'-AAGATATTACC ATGGTTAGTGTG-3' to introduce an NcoI site spanning the TsCHS2 initiation codon (Howles 1992). The TsCHS2 5'untranslated region was then cloned in front of the $\mathrm{NcoI}$ site spanning the initiator codon of a gusA coding sequence terminated by the pea vicilin 3' sequence (Djordjevic et al. 1997). Following the addition of EcoRI linkers (New England Biolabs, Beverly, MA), this chimeric reporter gene was cloned into the unique EcoRI site between the T-DNA borders of the binary transformation vector pTAB10 (Khan et al. 1994). The resulting plasmid pJJ402, confirmed by restriction enzyme analysis and hybridization probing, was transferred into the $A$. tumefaciens strain AGL1 (Lazo et al. 1991) for clover transformation.

\section{Microscopy and microspectrofluorometry.}

Sectioning, fluorescence microscopy, microspectrofluorometry and photography were done as described in Mathesius et al. (1998a). Toluidine blue staining was done on fresh vibratome sections with $0.05 \%$ toluidine blue $(\mathrm{pH} 4.4)$. Root hair deformations were examined on intact roots under bright 
field conditions with an Optiphot light microscope (Nikon, Tokyo). GFP was visualized under a Nikon Optiphot Fluorescence Microscope with a blue excitation filter (maximum excitation at $495 \mathrm{~nm}$ ) and a $505 \mathrm{~nm}$ dichroic mirror. Micrographs were taken on Fujichrome Provia 400 ASA color slide film (Fuji, Toyko).

\section{Extraction of compounds from white clover roots.}

Roots of white clover were extracted and the extracted compounds were HPLC-purified and identified as described in Mathesius et al. (1998a). All extractions were conducted three times in independent experiments. For quantification of the purified compounds, the areas under the peaks that were detected at $300 \mathrm{~nm}$ absorbance were calculated for each extraction and Student's $t$ tests were done to compare the amounts of compound present in mock-inoculated with those present in rhizobia-inoculated root extracts.

\section{Construction of ANU843(GFP).}

The R. leguminosarum bv. trifolii strain ANU843(GFP) was produced following the introduction of pHC60 into strain ANU843 by a triparental mating procedure. Plasmid pHC60 (gift of Haiping Cheng, MIT, Cambridge, MA) is a spontaneous mutant of pHC41 (Cheng and Walker 1998) that constitutively expresses the green fluorescent protein (GFP-S65T) (H. Cheng, personal communication).

\section{Statistical analysis.}

Student's $t$ tests and regression analysis were calculated with Excel 5.0 (Microsoft, Redmond, WA). Chi square tests were calculated with InStat Version 1.12 (Graph Pad Software, San Diego, CA).

\section{ACKNOWLEDGMENTS}

U. M. was supported by an Overseas Postgraduate Research Scholarship from the Australian Government. We thank Milutin Stoilovic (Australian Federal Police, Weston, ACT) for providing the microspectrofluorometer, M. E. McCully and C. Bayliss (Carleton University, Ottawa, Canada) for discussions and help with microspectrofluorometry, and Elena Gärtner for critical reading of the manuscript.

\section{LITERATURE CITED}

Arioli, T., Howles, P. A., Weinman, J. J., and Rolfe, B. G. 1994. In Trifolium subterraneum, chalcone synthase is encoded by a multigene family. Gene 138:79-86.

Bauer, P., Ratet, P., Crespi, M. D., Schultze, M., and Kondorosi, A. 1996. Nod factors and cytokinins induce similar cortical cell division, amyloplast deposition and Msenod12A expression in alfalfa roots. Plant J. 10:91-105.

Bhuvaneswari, T. V., Bhagwat, A. A., and Bauer, W. D. 1981. Transient susceptibility of root cells in four common legumes to nodulation by rhizobia. Plant Physiol. 68:1144-1149.

Bhuvaneswari, T. V., Turgeon, B. G., and Bauer, W. D. 1980. Early events in the infection of soybean (Glycine max L. Merr) by Rhizobium japonicum. Plant Physiol. 66:1027-1031.

Boot, K. J. M., van Brussel, A. A. N, Tak, T., Spaink, H. P., and Kijne, J. W. 1999. Lipochitin oligosaccharides from Rhizobium leguminosarum bv. viciae reduce auxin transport capacity in Vicia sativa subsp. nigra roots. Mol. Plant-Microbe Interact. 12:839-844.

Caetano-Anollés, G., Crist-Estes, D. K., and Bauer, W. D. 1988. Chemotaxis of Rhizobium meliloti to the plant flavone luteolin requires functional nodulation genes. J. Bacteriol. 170:3164-3169.

Chandler, M. R. 1978. Some observations on the infection of Arachis hypogaea L. by Rhizobium. J. Exp. Bot. 29:749-755.
Cheng, H.-P., and Walker, G. 1998. Succinoglycan is required for initiation and elongation of infection threads during nodulation of alfalfa by Rhizobium meliloti. J. Bacteriol. 180:5183-5191.

Dénarié, J., Débellé, F., and Promé, J.-C. 1996. Rhizobium lipo-chitooligosaccharide nodulation factors: Signalling molecules mediating recognition and morphogenesis. Annu. Rev. Biochem. 65:503-535.

Djordjevic, M. A., Mathesius, U., Arioli, T., Weinman, J. J., and Gärtner, E. 1997. Chalcone synthase gene expression in transgenic subterranean clover correlates with localised accumulation of flavonoids. Aust. J. Plant Physiol. 24:119-132.

Djordjevic, M. A., Redmond, J. W., Batley, M., and Rolfe, B. G. 1987. Clovers secrete specific phenolic compounds which either stimulate or repress nod gene expression in Rhizobium trifolii. EMBO J. 6: 1173-1179.

Ducket, C. M., Oparka, K. J., Prior, D. A. M., Dolan, L., and Roberts, K. 1994. Dye-coupling in the root epidermis of Arabidopsis is progressively reduced during development. Development 120:3247-3255.

Fåhraeus, G. 1957. The infection of clover root hairs by nodule bacteria studied by a simple glass slide technique. J. Gen. Microbiol. 16:374381.

Hirsch, A. M., and LaRue, T. A. 1997. Is the legume nodule a modified root or stem or an organ sui generis? Crit. Rev. Plant Sci. 16:361-392.

Howles, P. A. 1992. A molecular characterisation of phenylpropanoid genes of Trifolium subterraneum. Ph.D. thesis. Australian National University, Canberra.

Khan, M. R. I., Tabe, L. M., Heath, L. C., Spencer, D., and Higgins, T. J. V. 1994. Agrobacterium-mediated transformation of subterranean clover. Plant Physiol. 105:81-88.

Larkin, P. J., Gibson, J. M., Mathesius, U., Weinman, J. J., Gärtner, E., Hall, E., Tanner, G. J., Rolfe, B. G., and Djordjevic, M. A. 1996. Transgenic white clover. Studies with the auxin responsive promoter, GH3, in root gravitropism and lateral root development. Transgenic Res. 5:325-335.

Lazo, G. R., Stein, P. A., and Lugwig, R. A. 1991. A DNA transformation-competent Arabidopsis genomic library in Agrobacterium. Bio/Technology 9:936-967.

Li, Y., Wu, Y. H., Hagen, G., and Guilfoyle, T. 1999. Expression of the auxin-inducible GH3 promoter/GUS fusion as a useful molecular marker for auxin physiology. Plant Cell Physiol. 40:675-682.

Mathesius, U. 1999. Analysis of signal transduction during the Rhizobium-legume symbiosis using transgenic plants. Ph.D. thesis. Australian National University, Canberra.

Mathesius, U., Bayliss, C., Weinman, J. J., Schlaman, H. R. M., Spaink, H. P., Rolfe, B. G., McCully, M. E., and Djordjevic, M. A. 1998a. Flavonoids synthesized in cortical cells during nodule initiation are early developmental markers in white clover. Mol. Plant-Microbe Interact. 11: 1223-1232.

Mathesius, U., Schlaman, H. R. M., Spaink, H. P., Sautter, C., Rolfe, B. G. and Djordjevic, M. A. 1998b. Auxin transport inhibition precedes nodule formation in white clover roots and is regulated by flavonoids and derivatives of chitin oligosaccharides. Plant J. 14:23-34.

McCully, M. E. 1975. The development of lateral roots. Pages 105-124 in: The Development and Function of Roots. J. G. Torrey and D. T. Clarkson, eds. Academic Press, London.

McIver, J., Djordjevic, M. A., Weinman, J. J., and Rolfe, B. G. 1993. Influence of Rhizobium leguminosarum biovar trifolii host specific nodulation genes on the ontogeny of clover nodulation. Protoplasma 172:166-179.

Nutman, P. S. 1948. Physiological studies on nodule formation I. The relation between nodulation and lateral root formation in red clover. Ann. Bot. 12:81-96.

Nutman, P. S. 1956. The influence of the legume in root nodule symbiosis. Biol. Rev. 31:109-151.

Phillips, D. A. 1992. Flavonoids: Plant signals to soil microbes. Pages 201-231 in: Phenolic Metabolism in Plants. H. A. Stafford and R. K. Ibrahim, eds. Plenum, New York.

Redmond, J. R., Batley, M., Djordjevic, M. A., Innes, R. W., Keumpel, P. L., and Rolfe, B. G. 1986. Flavones induce expression of nod genes in Rhizobium. Nature 323:632-635.

Rolfe, B. G. 1988. Flavones and isoflavones as inducing substances of legume nodulation. BioFactors 1:3-10.

Rolfe, B. G., Gresshoff, P. M., and Shine, J. 1980. Rapid screening for symbiotic mutants of Rhizobium and white clover. Plant Sci. Lett. 19: 277-284. 
Rolfe, B. G., and McIver, J. 1996. Single-leaf plantlet bioassays for the study of root morphogenesis and Rhizobium nodulation. Aust. J. Plant Physiol. 23:271-283.

Spaink, H. P. 1996. Regulation of plant morphogenesis by lipo-chitin oligosaccharides. Crit. Rev. Plant Sci. 15:559-582.

Tschermak-Woess, E., and Dolezal, R. 1953. Durch Seitenwurzelbildung induzierte und spontane Mitosen in den Dauergeweben der Wurzel. Oesterr. Bot. Z. 100:358-402.

Tsien, H. C., Dreyfus, B. L., and Schmidt, E. L. 1983. Initial stages in the morphogenesis of nitrogen-fixing stem-nodules of Sesbania rostrata. J. Bacteriol. 156:888-897.

van Brussel, A. A. N., Bakhuizen, R., van Spronsen, P. C., Spaink, H. P.,
Tak, T., Lugtenberg, B. J. J., and Kijne, J. W. 1992. Induction of preinfection thread structures in the leguminous host plant by mitogenic lipo-oligosaccharides of Rhizobium. Science 257:70-71.

Yang, W.-C., de Blank, C., Maskiene, I., Hirt, H., Bakker, J., van Kammen, A., Franssen, H., and Bisseling, T. 1994. Rhizobium Nod factors reactivate the cell cycle during infection and nodule primordium formation, but the cell cycle is only completed in primordium formation. Plant Cell 6:1415-1426.

Yang, W.-C., Katinakis, P., Hendriks, P., Smolders, A., de Vries, F., Spee, J., van Kammen, A., Bisseling, T., and Franssen, H. 1993. Characterisation of GmENOD40, a gene showing novel patterns of cell-specific expression during soybean nodule development. Plant J. 3:573-585. 